\title{
IMPLEMENTATION OF QUALITY MANAGEMENT SYSTEM FOR IRRADIATION PROCESSING SERVICES
}

\author{
LUNGU Ion-Bogdan \\ Centre of Technological Irradiations - IRASM, Horia Hulubei National Institute for R\&D in Physics and \\ Nuclear Engineering - NIPNE-HH, Magurele, Romania, ion.lungu@nipne.ro \\ MANEA Maria-Mihaela \\ Centre of Technological Irradiations - IRASM, Horia Hulubei National Institute for R\&D in Physics and \\ Nuclear Engineering - NIPNE-HH, Magurele, Romania, mmanea@nipne.ro
}

\begin{abstract}
In today's market, due to an increasing competitiveness, quality management has set itself as an indispensable tool and a reference point for every business. It is ultimately focused on customer satisfaction which is a stringent factor for every business. Implementing and maintaining a QMS is a rather difficult, time consuming and expensive process which must be done with respect of many factors. The aim of this paper is to present a case study for implementing QMS ISO 9001 in a gamma irradiation treatment service provider. The research goals are the identification of key benefits, reasons, advantages, disadvantages, drawbacks etc for a successful QMS implementation and use. Finally, the expected results focus on creating a general framework for implementing an efficient QMS plan that can be easily adapted to other kind of services and markets.
\end{abstract}

Key words: quality management system, implementation, radiation processing, customer satisfaction

\section{Introduction}

Nowadays, quality management system (QMS) is grouped around ISO 9000 series, quality management standards and guidelines, which has earned a global reputation as a basis for establishing effective and efficient quality management systems [1].

In the year 1987 it was published the first ISO 9000 based on the British Standard BS 5750. Now, it addresses various aspects of QMS and contains some of ISO's best known standards: ISO 9001: 2015 sets out the requirements of a quality management system; ISO 9000: 2005 - covers the basic concepts and language; ISO 9004: 2009 - focuses on how to make a QMS more efficient and effective. ISO 19011: 2011 - sets out guidance on internal and external audits of QMS [2]. These standards are designed as guidelines and requirements in order to ensure companies that it provide products and services according to customer's requirements with consistently improved quality.

A successful implementation of QMS needs a thorough understanding of terms like [3]: quality refers to the perception of the extent to which a product or service meets the customer's expectations. Alone, quality has no explicit meaning, unless it is related to a specific set of requirements, that's why ISO defines quality as the degree to which a set of inherent characteristics fulfils requirements; quality management - a process that focuses both on the quality of the product and on the means to achieve it. It is focused on: quality planning, quality control, quality assurance and quality improvement; quality management system: the organizational structure, procedures, processes and resources required to ensure the delivery of an organization's quality products and services; quality assurance: instill confidence that quality requirements have been met. It involves a systematic monitoring and evaluation of the processes associated with the generation of a product or service; quality assessment - the measure of a customer's satisfaction directly related to quality definition; quality management system implementation: the execution or practice of a project, a method, etc. for improving quality. Implementation is the action that must follow any preliminary thinking or planning in order for anything to actually happen. In quality context, implementation encompasses the processes, involved at all levels - operational, management and external - in achieving the objectives of the organization.

There are several key reasons for implementing a quality management system. The first derives from businesses' globalization as more organizations operate in the global economy through commerce, selling or buying products and services from providers outside their national market; sometime a quality 
management system is mandatory for business collaboration. Second refers to improve quality and organizational efficiency whether it is through cost reductions, eliminating defects or waste, improving processes and procedures, changing the organizational culture or adding quality control as a top priority [4]. Third, when seeking to establish and prove a certain status of quality level for a particular business used on a certain market, that provides confidence in a company's ability to deliver products or services that fulfill customer needs and expectations. Last but not least, one reason is represented basically by financial benefits and potential of business growth achieved through market share, cost reduction obtained from improving collaboration with external partners, i.e. customers and suppliers, negotiate optimally and assess human and material resources needed for operation and sell products and services at best price and obtaining a high profit.

\section{IRASM radiation processing centre}

Industrial radiation processing in Romania is concentrated at IRASM irradiation processing centre, under the administrative umbrella of NIPNE-HH (National Institute of Physics and Nuclear Engineering - Horia Hulubei), a R\&D nuclear institute. IRASM holds the only industrial irradiator in Romania, operating since 2000, a result of a technical cooperation project between IAEA and Romanian Government, under the name "Multipurpose Irradiation Facility". Its first goal is the promotion of technological irradiation in Romania and abroad; it is both R\&D and client oriented, offering industrial irradiation services, consulting, analyses, training and research in radiation processing.

Radiation processing can be considered as two complementary processes, depending on the required standards: sterilization, mainly for medical and pharmaceutical industry and decontamination. Radiation sterilization is a well established and highly standardized method for sterilization of single use medical supplies (syringes, catheters, needles, cotton gauzes, dental implants, Petri dishes etc.), sterilization for primary packaging materials (bottles, dispensers, gelatine capsules, sterile drugs etc.) and pharmaceutical products.

Decontamination process is required in any domain in which the products have regulatory limits for microbial load (bio-burden). In this case, gamma irradiation can be used for bio-burden reduction. It can be applied for final products but also for raw materials, packages and other additives. When talking about irradiation dose, decontamination requires lower doses than sterilization. The control of bio-burden is used to a wide range of materials like primary products for pharmaceutical industry (titan oxide, magnesium lactate etc), foodstuff for animals, organic support for micro and micro-organisms, dry herbs (tea), dietary supplement (capsules, tablets) and packaging products (cups, bottles, foils etc).High volume and complex devices can be processed for disinfection (water purification equipment, cleaning and protection equipment, beehives etc). This service addresses customers from medical, pharmaceutical and cosmetic domains, food industry, dietary supplements manufacturers, packaging domain and any other industry where microbiological safety is a requirement.

The end-users can benefit not only from the irradiation treatment but also pre-irradiation and post-irradiation microbiological tests and product irradiation qualification.

\section{Implementation of quality management system}

It is very important that implementation must be made for the right reasons, so it is necessary to identify why a QMS should be implemented. The main objective resides in the need to establish an environment of quality assurance and quality control based on interacting processes, ensuring that proper standards are met and maintained. Nevertheless, most customers from medical and pharmaceutical industries require a quality accreditation from its suppliers. Taking into consideration that most requirements for radiation treatment come from medical and pharmaceutical companies, a market that is very well standardized, the main reason is to create the premises for a maximum market share, such as being able to provide services even for highly demanding customers. Second reason is the quality assurance which has big implication for these markets; if a product is considered sterile but in reality is not, the consequences can be very serious. Third, a right on time delivery is required for such customers, that's why procedures like reception, storage, radiation treatment, expedition of products, maintenance of the industrial irradiator, traceability forms etc. can assure such a stringent requirement.

A tangential requirement is to identify the benefits of a quality management system. Some of the most important can be grouped in high profit and customer satisfaction: flexibility and fast response to opportunities, customer loyalty, effective use of resources, improved, consistent and predictable results, focused and prioritized improvement opportunities, integration and alignment of the processes, providing confidence to interested parties as to the consistency, effectiveness and efficiency of the organization etc.

After identification of reasons and benefits which conclude to the decision of implementing the QMS, there is the need to assess the actual level of capabilities, strength and weaknesses of the 
organization regarding quality management. The results will reflect the degree of effort that the implementation will require. The implementation plan was shaped according to several business and organization characteristics and with respect of its requirements.

1) Type of industry: service provider for sterilization and decontamination of different products;

2) Company size: around 30 people from which 20 are directly involved;

3) Key process: gamma irradiation service;

4) Products: refer to the type of processed goods (mentioned above).

Implementing QMS at IRASM irradiation processing centre was successful due to the fact of small number and highly qualified personnel and high regulated process which led to fully learning, adopting and following quality requirements. standards.

The implementation plan followed the standard recommended framework of ISO 9000 quality

1. Top management engagement: identification of reasons and benefits as a result of QMS implementation, analysis of company characteristics and the level of organization regarding quality management (mentioned above). Defining the following: policy - to maintain a high level of customer satisfaction through continuous assurance and improvements of services through developing, documenting and maintaining a comprehensive quality management program; quality objectives: vision increasing the prestige and credibility of services provided and the development of the organization; values - professionalism, enthusiasm, competence, skilled personnel, receptive to customer and also societies' needs and requirements.

2. Define key processes: a key process can be identified when it has a high level of negative impact when it fails to consistently and effectively be controlled and if the outcome cannot easily be reversed or corrected. At IRASM irradiation centre it is represented by the irradiation service (sterilization and decontamination) for medical and pharmaceutical products.

3. Define QMS requirements according to ISO 9001: it is composed by five sections and it represents the core for a succesful QMS implementation. All the paragraphs (if applicable) for each section must be analyzed, explained and detailed with proofs (documents) according to organizations' particularities. Each section ends with reference documents i.e. procedures, work instructions, manuals, programs etc.

1) Overall requirements for the quality management system and documentation:

- quality management system: defines the processes and interactions between them. For example the processes of management, internal and external comunication, resources management and allocation, grouped in core processes: irrradiation treatment followed by dosimetry etc and support processes e.g. identification and traceability forms followed by measurement and monitoring and non-conforming products and complaints etc. At this stage, the structure of QMS is represented in figure 1.

Figure 1: Structure of QMS
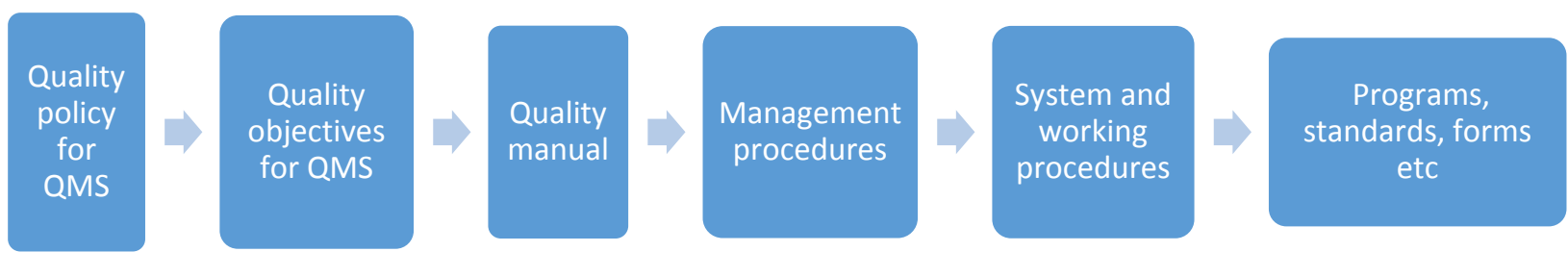

- documentation requirements: in order to plan, conduct and control the processes it is necessary to create certain documents to satisfy quality objectives; procedures are created and grouped in management, system and operational documents, work instructions, quality manual, quality policy etc. Finally, the documents and their records must be controlled.

2) Management responsibility: covers the demanded level of management commitment, customer focus, quality policy, planning, responsibility, authority and communication. Evidence is shown through quality manual and different procedures like organization policy, quality objectives, planning of QMS, techological dosimetry etc. For example, customer focus is proved by a series of actions like respecting the contract terms, analysis of sugestions and complains followed by answers, allowing audits for the QMS etc and defining an operational procedure like „Informations regarding customer satisfactions”.

3) Resource management and allocation: it includes provision of resources, human resources, infrastructure, and work environment. Its scope is to determine and provide the resources needed to maintain and continually improve the effectiveness of the QMS in order to meet customer requirements. For example „Procedure for training” was defined, wher it is described the necessary steps to attain the required level of knowledge for the employees. 
4) Product realization and process management: IRASM centre provides only services, ionizing radiation treatment. It starts with planning followed by understanding and agreeing to customer requirements, design, purchasing, control and validation of processes, identification and care of products, and control of monitoring and measuring devices. For example, the irradiation treament is discribed as a flowchart in „Procedure for technological irradiation”.

5) Measurement, monitoring, analysis and improvement: IRASM developed and maintains a system for tracking, colecting and analysis of data for the good functioning of QMS and also for its continuous improvement. Some of the actions are conducted through internal audits, monitoring the performances of processes and services and assessment of customer satisfaction.

4. Maping the QMS structure: QMS is build within the quality manual which is the core and official document and framework for the people within an organization; it also guides the internal activities. It is a reference for certification and assessment of QMS, a support for personal training and for continuous improvement of QMS. Within the quality manual it is described the sequence and interaction of QMS processes: customer's requirements (inputs) - QMS - customer's satisfaction (outputs).

5. Obtain an accreditation certificate from an accreditation body for ISO 9001: accreditation from DQS Romania.

\section{Conclusions}

Building and implementing a standardized QMS is rather difficult even if the organization had prior procedures, quality objectives, policies etc. In general, adding a new organizational system determine the organization to change and adapt its original system and procedures to the new one which is very difficult in practice. Nevertheless, implementing and maintaining a QMS for other reasons than stated will burden the organization with extra costs and useless mandatory documents without benefits. Even after implementing QMS there are possibilities in recurrent problems such as poor system quality, employee dissatisfaction and high costs due to long development time. The cost of poor QMS reflects on the service provided with errors, a fact which leads to rework and rectifications of QMS basic documents and, in most cases in loosing customers.

But when talking to the outcomes of an efficient QMS most people say it is worth all the effort, cost and risk. First, accreditation is a powerful tool to establish credibility and accountability for business and customers are reassured that the organization objectives are linked to their needs and expectations; it continuously measure customer satisfaction and acts on the results leading to high benefits. Another factor is represented by motivated, committed and involved people who are accountable for their own performance, they gain new competencies through constant training. They are seeking opportunities to enhance their competence, knowledge and experience and evaluate their performance against their personal goals and objectives. QMS can be used as a marketing tool for promoting the organization and also a mark that it distinguish it from competitors.

Last but not least,obtaining ISO 9001 certification is not an end in itself but an important component of the overall continuous improvement process and quality.

IRASM tehnological irradiation centre implemented ISO 9001 QMS in order to provide a highly standardized service like sterilization. This led to an acreditation by DQS - Germany, for the following certificates: SR EN ISO 9001 - Quality Management System; SR EN ISO 13485 - Medical devices; SR EN ISO 15378 - Primary packaging materials for medicinal products (particular requirements for the application of ISO 9001:2008, with reference to Good Manufacturing Practice, (GMP) (obtained in 2014); SR ISO 11137 - Sterilization of health care products (Radiation). The field of medical devices and pharmaceuticals are regulated by EU Directives (90/385/EEC, 93/42/EEC, 98/79/EC) and GMP (EudraLex - Volume 4). All services offered to customers are performed according to QMS and it is in compliance with the applicable international standards.

\section{References}

- http://www.iso.org/iso/iso_9000_selection_and_use-2009.pdf.

- http://www.iso.org/iso/iso_9000.

- World Meteorological Organization, Guide to the Implementation of a Quality Management System for National Meteorological and Hydrological Services, ISBN 978-92-63-11100-8, 2013.

- David Sandström, Marcus Svanberg, Preparing to overcome the barriers of implementing a quality management system: - A case study of EDB Card Services AS, http://www.divaportal.org/smash/get/diva2:499992/FULLTEXT01.pdf. 